\title{
Mechanical clinching and self-pierce riveting for sheet combination of 780-MPa high-strength steel and aluminium alloy A5052 sheets and durability on salt spray test of joints
}

\author{
Yohei Abe ${ }^{1}$ (D) $\cdot$ Ken-ichiro Mori ${ }^{1}$ \\ Received: 1 July 2020 / Accepted: 18 December 2020 / Published online: 20 January 2021 \\ (C) The Author(s) 2021
}

\begin{abstract}
To increase the usage of high-strength steel and aluminium alloy sheets for lightweight automobile body panels, the joinability of sheet combinations including a 780-MPa high-strength steel and an aluminium alloy A5052 sheets by mechanical clinching and self-pierce riveting was investigated for different tool shapes in an experiment. All the sheet combinations except for the two steel sheets by self-pierce riveting, i.e., the two steel sheets, the two aluminium alloy sheets, and the steel-aluminium alloy sheets, were successfully joined by both the joining methods without the gaps among the rivet and the sheets. Then, to show the durability of the joined sheets, the corrosion behaviour and the joint strength of the aged sheets by a salt spray test were measured. The corrosion and the load reduction of the clinched and the riveted two aluminium alloy sheets were little. The corrosion of the clinched two steel sheets without the galvanized layer progressed, and then the load after $1176 \mathrm{~h}$ decreased by $85 \%$. In the clinched two galvanized steel sheets, the corrosion progress slowed down by $24 \%$. In the clinched steel and aluminium alloy sheets, the thickness reduction occurred near the minimum thickness of the upper sheet and in the upper surface on the edge of the lower aluminium alloy sheet, whereas the top surface of the upper sheet and the upper surface of the lower sheet were mainly corroded in the riveted joint. The load reduction was caused by the two thickness reductions, i.e., the reduction in the minimum thickness of the upper sheet and the reduction in the flange of the aluminium alloy sheet. Although the load of the clinched steel without the galvanized coating layer and aluminium alloy sheets decreased by about $20 \%$, the use of the galvanized steel sheet brought the decrease by about $11 \%$. It was found that the use of the galvanized steel sheets is effective for the decrease of strength reduction due to corrosion.
\end{abstract}

Keywords Joining $\cdot$ Mechanical joining $\cdot$ Mechanical clinching $\cdot$ High-strength steel sheets $\cdot$ Aluminium alloy sheet $\cdot$ Corrosion . Salt spray test $\cdot$ Joint strength

\section{Introduction}

To reduce the weight of automobiles, the application of highspecific-strength sheets to body parts is increasing. Highstrength steel sheets with higher strength than conventional mild steel sheets, ultra-high-strength steel sheets with a tensile strength of $1 \mathrm{GPa}$ or more, and aluminium alloy sheets with low-specific density have been used as high-specific strength sheets. Steel body parts are generally assembled by resistance

Yohei Abe

abe@plast.me.tut.ac.jp

1 Faculty of Engineering, Toyohashi University of Technology, 1-1 Tempaku-cho, Toyohashi, Aichi 441-8580, Japan spot welding after the stamping process. However, joining two aluminium alloy sheets and joining the aluminium alloy and steel sheets are not easy by resistance spot welding because of the high thermal conductivity, the surface oxide layer, and the lower melting point of aluminium alloy sheet [1]. Instead of the welding process, the joining process by mechanical fastening such as mechanical clinching and selfpierce riveting is used for these sheet combinations in automobile body parts. Not only the joinability of steel and aluminium alloy sheets but also the joinability of both the same material is important to increase the usage of high-strength steel and aluminium alloy sheets for lightweight automobile body parts.

In mechanical clinching, two sheets are generally joined by local hemming with a pair of punch and die without subsidiary materials such as rivets. Mechanical clinching is widely used 
for electrical appliances and automobiles [2]. He [3] reviewed the mechanical clinching process, and various research works have been conducted. Mechanical clinching processes are developed to join aluminium alloy sheets [4], high-strength steel sheets [5], ultra-high-strength steel sheets [6], boron steel sheets in hot stamping [7], aluminium alloy and mild steel sheets [8], aluminium alloy and high-strength steel sheets [9], carbon fibre-reinforced plastic and aluminium alloy sheets [10], and steel sheet and aluminium casting [11], respectively. Although some technologies such as local cutting and upsetting of the sheets with rectangular tools are used in some mechanical clinching processes, round clinching is very common.

In self-pierce riveting, the sheets are pierced with a tubular rivet without a pre-hole. The rivet is driven through the upper sheet and the rivet tip is flared in the lower sheet to form an interlock for hooking the lower sheet on the flared tip. Selfpierce riveting is widely used for two sheets including aluminium alloy sheet in automobile parts. Mori et al. [12] reviewed the mechanical joining including the self-pierce riveting and mechanical clinching processes. Joinabilities of self-pierce riveting are investigated to join aluminium alloy sheets [13], aluminium alloy and mild steel sheets [14], aluminium alloy and high-strength steel sheets [15], aluminium alloy and coated steel sheet [16], and metal sheet-polymer [17], i.e., many sheet combinations for joining automobile parts are possible to join by self-pierce riveting and mechanical clinching. The joinability and the joint strength with a same sheet combination including the high-strength steel and aluminium alloy sheets of joined by clinching and riveting are not clear.

Although the assembled parts are painted to have corrosion protection, it is important to understand the strength reduction of joints due to corrosion without painting as a basic knowledge. In steel sheets, the corrosion resistance can be improved by having surface coating layers such as galvanized steel sheets, and galvanized steel sheets are commonly used in automobile parts. In mechanical clinching of hot-dip zincaluminium-magnesium alloy-coated steel sheets, the thickness layer of coating was reduced by the sever deformation in clinching, and the reduction was reduced by modification of tool shape [18]. The corrosion resistance of galvanized steel parts in the clinch joints was improved by using the galvanized coating layers having a high ductility [19]. The electrochemical corrosion behaviour of the aluminium alloy was changed by the plastic deformation [20]. The corrosion behaviour of the rivet and A6000 series aluminium alloy sheets was evaluated by means of potentiodynamic polarisation test, and then corrosion degradation of the joint due to crevice and pitting phenomena reduced the durability of the joint [21]. Ioannou [22] investigated the corrosion behaviour of the self-piercing riveted interstitial-free steel and aluminium alloy joints. The fracture behaviours of aged the aluminium alloy and high-strength steel sheets joined by clinching [23] and riveting [24] were changed. Although Calabrese et al. [24] showed the failure behaviour of self-pierce riveted joints of the 570-MPa steel and A6000 aluminium alloy sheets after salt spray test, the gaps among the rivet and the sheets in the cross-section were allowed. The effects of the higher strength steel sheet and the joint without the gaps are attractive in the industry. The obtained knowledge was effective for each case, whereas it is not easy to compare with these results because these studies were carried out under the various corrosion tests and sheet combinations. The corrosion performance and the mechanical properties of joined automotive materials were investigated for a low-carbon steel and an aluminium alloy sheets [25]. Although the many test are performed for the evaluation of the durability of in joints, the salt spray test is a basic test method for the evaluation of the joints in the automobile parts. It is desirable to evaluate durability on a same corrosion test with a same sheet combination including the high-strength steel and aluminium alloy sheets of joined by clinching and riveting.

In this study, mechanical clinching and self-pierce riveting were performed on the sheet combinations including 780MPa high-strength steel and aluminium alloy A5052 sheets, and then the optimum conditions to have the maximized interlock were obtained. To show the durability of joints, and to compare with the self-pierce riveted joints, the corrosion behaviour and joint strength of the aged joints by the salt spray test were measured.

\section{Mechanical clinching of high-strength steel and aluminium alloy sheets}

\subsection{Sheet combinations}

The sheet combinations are shown in Table 1. The highstrength steel (JSC780) sheets having $780 \mathrm{MPa}$ of tensile strength in 1.2-mm thickness were used, and the effect of galvanized steel (JAC780) sheets was investigated. The aluminium alloy A5052 sheets having $1.0-\mathrm{mm}$ and $1.5-\mathrm{mm}$ thickness were used. The 780-MPa high-strength steel sheet

Table 1 Sheet combinations

\begin{tabular}{lllll}
\hline Upper sheet & & & \multicolumn{2}{l}{ Lower sheet } \\
\cline { 1 - 2 } \cline { 5 - 5 } Material & Thickness (mm) & & Material & Thickness (mm) \\
\hline A5052-H34 & 1.5 & & A5052 & 1.5 \\
JSC780 & 1.2 & & JSC780 & 1.2 \\
JAC780 & 1.2 & & JAC780 & 1.2 \\
JSC780 & 1.2 & & A5052 & 1.5 \\
JAC780 & 1.2 & A5052 & 1.5 \\
JSC780 & 1.2 & A5052 & 1.0 \\
\hline
\end{tabular}


Table 2 Material properties of sheets

\begin{tabular}{lllll}
\hline Material & Coating layer & Thickness $(\mathrm{mm})$ & Tensile strength (MPa) & Elongation (\%) \\
\hline JSC780 & - & 1.20 & 799 & 19.2 \\
JAC780 & Galvanized & 1.21 & 791 & 19.4 \\
A5052 & - & 1.50 & 249 & 10.5 \\
& - & 1.00 & 229 & 9.2 \\
\hline
\end{tabular}

and the aluminium alloy sheet having 1.5-mm thickness were used as structure panels in the automobile body, and the aluminium alloy sheet having 1-mm thickness was used as outer panels. As the similar sheet combinations, the two aluminium alloy A5052 sheets having $1.5 \mathrm{~mm}$ and the two steel sheets were joined. As the dissimilar sheet combinations, the steel and aluminium alloy sheets were joined. The material properties of sheets are shown in Table 2 . These values were obtained by uniaxial tension test. The tensile speed was $10 \mathrm{~mm} / \mathrm{min}$ in the test.

\subsection{Conditions of mechanical clinching}

Joining by mechanical clinching is shown in Fig. 1. The punch pressed into the sheets held on the die. The pressed sheet material is compressed between the punch and the die bottoms, then the material flows in the radial direction, and finally an interlock is formed between the upper and lower sheets. The requirement for joining by mechanical clinching is to form an interlock without sheet fracture, and an appropriate interlock and a minimum thickness of the upper sheet are required to obtain the certain joint strength.

The conditions of mechanical clinching are shown in Fig. 2. A punch with 5.2-mm diameter was pressed into the sheets up to $60 \mathrm{kN}$. Since the joinability depends on the sheet combinations, the optimum clinching conditions were obtained by changing the die diameter $h$ and the die depth $d$. The specimen was a square shape with $30 \mathrm{~mm}$ on a side. The clinched sheets were cut, and the cross-section of the sheets was observed to measure the interlock and the minimum wall thickness in the

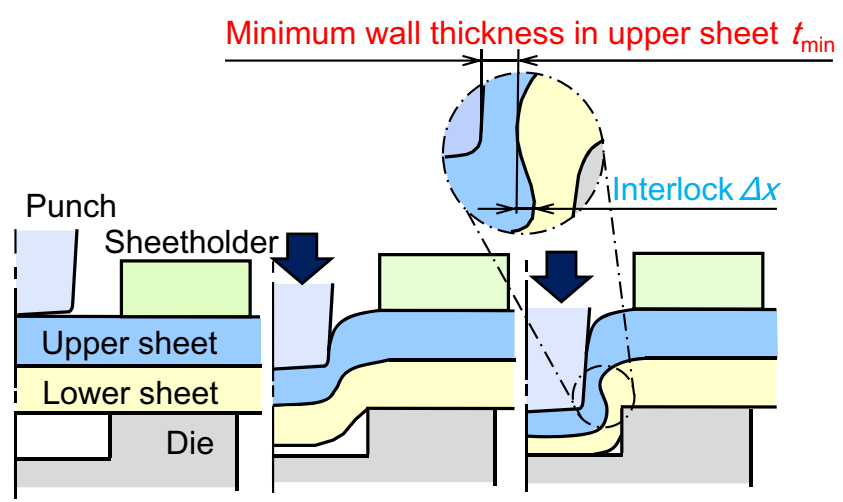

Fig. 1 Joining by mechanical clinching upper sheet. In these conditions, the intermetallic layers are not shown in the sheet interface because of cold joining.

\subsection{Optimum die shape}

The effect of the die shape on the minimum wall thickness in the upper sheet and the interlock for A5052-A5052 sheets is shown in Fig. 3. As the die depth increases, the minimum thickness of the upper sheet and the interlock decreases and increases, respectively. $h=1.4 \mathrm{~mm}$ was selected because fracture occurred at the minimum thickness of the upper sheet at $h$ $=1.6 \mathrm{~mm}$. At $h=1.4 \mathrm{~mm}$, the effect of the die diameter on the minimum thickness of the upper sheet is not large, and $d=$ $8.5 \mathrm{~mm}$ is the optimum value because of the maximum value of the interlock.

The effect of die shape on the minimum wall thickness in the upper sheet and the interlock for the 780-MPa steel sheets is shown in Fig. 4. The tendency is similar to the tendency in Fig. 3. The optimum die shape for the maximum interlock is $h$ $=1.8 \mathrm{~mm}$ and $d=8.5 \mathrm{~mm}$.

The effect of the die shape on the minimum wall thickness in the upper sheet and the interlock for the 780-MPa steel-A5052 sheets is shown in Fig. 5. The formation of the interlock seems to shift in the thin aluminium alloy sheet because the much material flow needs to form the interlock in the thin lower sheet. Therefore, to form the maximum interlock, $h=1.2 \mathrm{~mm}$ in $d=$ $8.5 \mathrm{~mm}$ is the optimum condition for $t=1.5 \mathrm{~mm}$, whereas $h=$ $1.4 \mathrm{~mm}$ in $d=8.5 \mathrm{~mm}$ is optimum for $t=1 \mathrm{~mm}$.

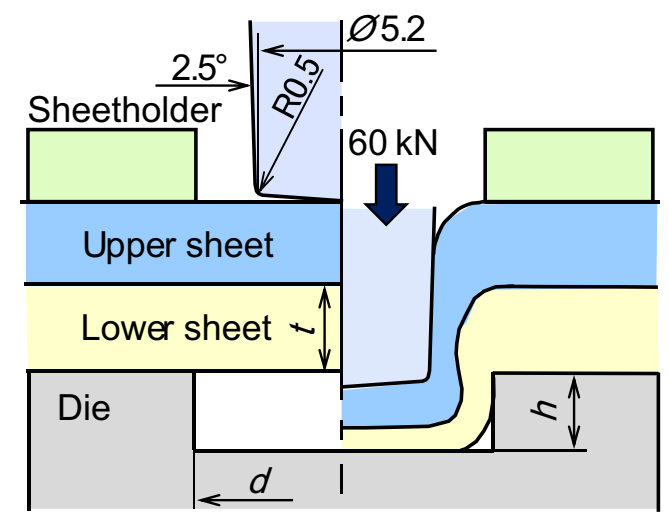

Fig. 2 Joining conditions of sheets by mechanical clinching 
Fig. 3 Effect of die shape on minimum wall thickness in upper sheet and the interlock for A5052A5052 sheets. a Die depth; b Die diameter

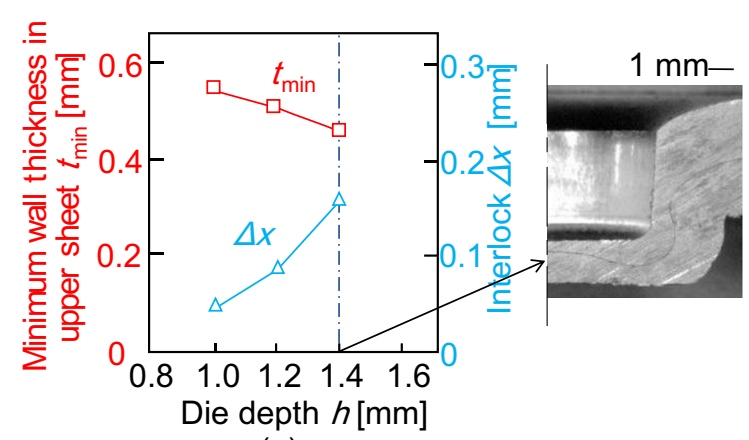

(a)

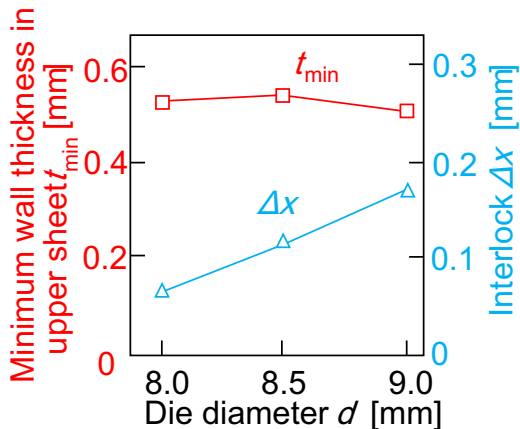

(b)

Fig. 4 Effect of die shape on minimum wall thickness in upper sheet and interlock for 780-MPa steel sheets. a Die depth; b Die diameter

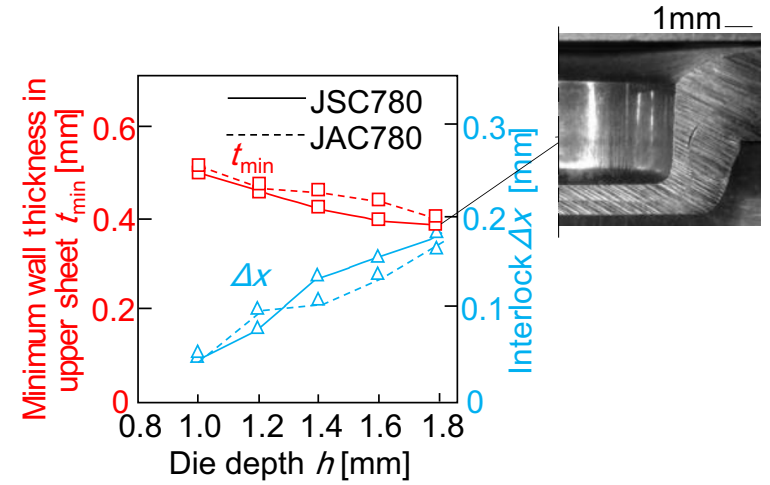

(a)

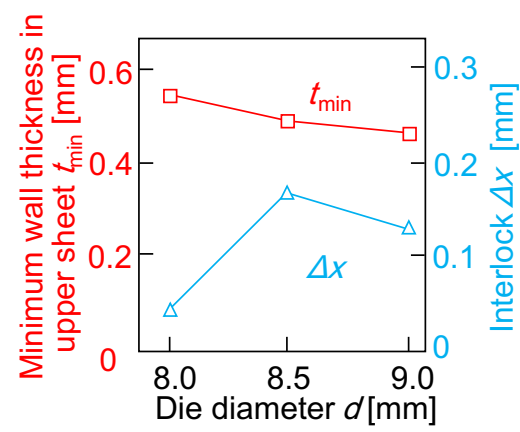

(b)
The sheet configuration and the optimum die shape in mechanical clinching are summarized in Table 3. The optimum die shape is used for each sheet configuration in the salt spray test specimen. In all joints, the occurrence of the gaps among the rivet and the sheet was prevented.

\subsection{Conditions of self-pierce riveting and joined sheets}

Joining by self-pierce riveting is shown in Fig. 6. In self-piercing riveting, the sheets are joined without a pre-hole by a rivet. The rivet is pressed into the sheets by a punch. The rivet tip pierces the upper sheet and then spreads in the lower sheet. Finally, an interlock to hook the sheets is formed between the rivet tip and the lower sheet. Joining the lower sheet without fracture is usually required to seal in the automobile body panels.

The joining conditions of sheets by self-pierce riveting are shown in Fig. 7. As a similar sheet combination, the two aluminium alloy sheets and the two 780-MPa steel sheets were joined by self-pierce riveting. As a dissimilar sheet combination, the 780-MPa steel and the aluminium alloy sheets were joined. The rivet having $480 \mathrm{HV}$ was made of boron
Fig. 5 Effect of die shape on minimum wall thickness in upper sheet and interlock for 780-MPa steel-A5052 sheets. a Die depth; b Die diameter

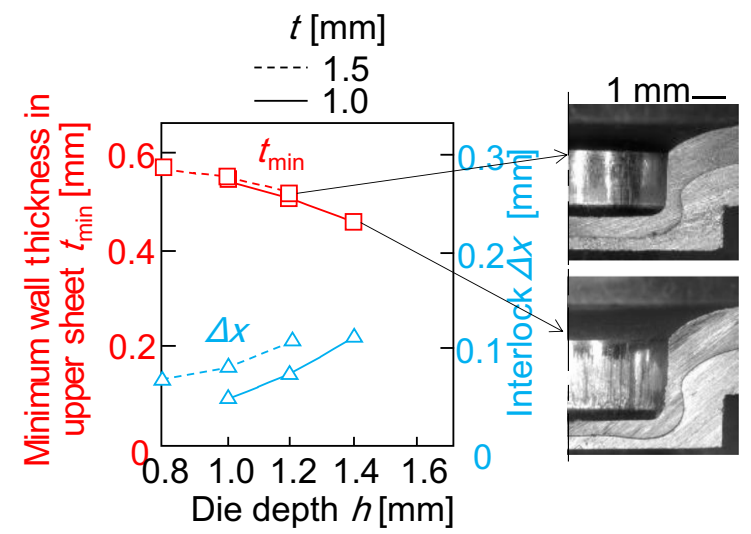

(a)

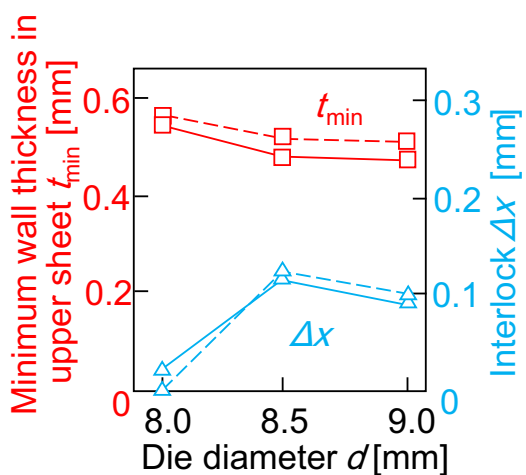

(b) 
Table 3 Sheet configuration and die shape for salt spray test

\begin{tabular}{|c|c|c|c|c|c|}
\hline \multicolumn{2}{|c|}{ Upper sheet } & \multicolumn{2}{|c|}{ Lower sheet } & \multicolumn{2}{|l|}{ Die shape } \\
\hline Material & Thickness (mm) & Material & Thickness (mm) & Diameter $d(\mathrm{~mm})$ & Depth $h(\mathrm{~mm})$ \\
\hline A5052 & 1.5 & A5052 & 1.5 & 9.0 & 1.4 \\
\hline JSC780 & 1.2 & JSC780 & 1.2 & 8.5 & 1.8 \\
\hline JAC780 & 1.2 & JAC780 & 1.2 & 8.5 & 1.8 \\
\hline JSC780 & 1.2 & A 5052 & 1.5 & 8.5 & 1.2 \\
\hline JAC780 & 1.2 & A5052 & 1.5 & 8.5 & 1.2 \\
\hline JSC780 & 1.2 & A5052 & 1.0 & 8.5 & 1.4 \\
\hline
\end{tabular}

steel, and the diameter of rivet tip was $5.3 \mathrm{~mm}$. Under the shaped die used to increase the interlock, the effect of the rivet length $L=4 \mathrm{~mm}$ and $5 \mathrm{~mm}$ was investigated. If the rivet length is too long, the gaps between sheets tend to occur. In these conditions, the intermetallic layers are not shown in the sheet interface because of cold joining.

The cross-sectional shapes of the riveted sheets are shown in Fig. 8. Except for the two 780-MPa steel sheets due to high flow stress of the sheets, all sheet combinations are joined by self-pierce riveting without defects. The gaps among the rivet and upper and lower sheets are not observed even in $L=5 \mathrm{~mm}$.

The effect of the rivet length on the interlock is shown in Fig. 9. The two aluminium alloy sheets and the steelaluminium alloy sheets are joined by $L=4 \mathrm{~mm}$ and $5 \mathrm{~mm}$. In the long rivet and the upper steel sheet, the interlock was increased because of large spreading of the rivet tip. In the two aluminium alloy sheets and the steel-aluminium alloy sheets in the salt spray test, $L=5 \mathrm{~mm}$ was used.

\section{Durability on salt spray test of joints}

\subsection{Conditions of salt spray test and tensile test}

The dimensions of specimens and the test conditions for the tensile test and the tension-shearing test are shown in Fig. 10.

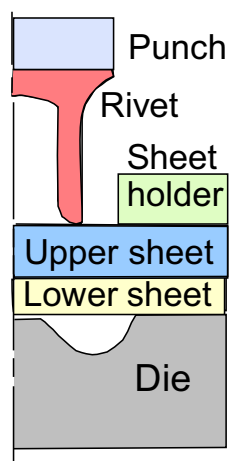

(a)

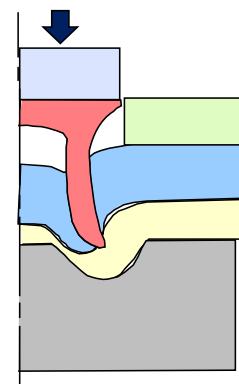

(b)

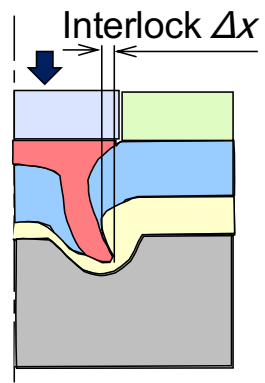

(c)
Fig. 6 Joining by self-pierce riveting. a Initial; b Piecing; $\mathbf{c}$ Formation of interlock
The specimen dimension was a square $30 \mathrm{~mm}$ on a side for observing the cross-section of joined sheets. In the centre of specimen, mechanical clinching was performed. To measure the tension-shearing load of the joined sheets, the specimen having $100-\mathrm{mm}$ length and $30-\mathrm{mm}$ width was used. The uniaxial tensile test specimen was also prepared for measuring the corrosion strength of the aged sheet. The tensile rate in the tension-shearing and the uniaxial tensile tests was $10 \mathrm{~mm} / \mathrm{min}$. The salt spray test for the specimens was carried out. The sheets were corroded by solution of $3.5 \%$ neutral sodium chloride at $35^{\circ} \mathrm{C}$. The maximum aging time was $1176 \mathrm{~h}$. The number of the test in a condition was two at least, and the average value was evaluated.

\subsection{Durability of sheets}

The reduction in the maximum tensile load of the aged sheet without the joint and the sheet thickness is shown in Fig. 11. As shown in Fig. 11a, the maximum load in the tensile test of the steel sheet decreases with increasing the corrosion time. For the steel sheets at $T=1176 \mathrm{~h}$, the load of the galvanized steel sheets JAC780 decreased to $88 \%$, and the load of the steel without the galvanized coating layers decreased to $63 \%$. For the aluminium alloy sheet, the load decreases to

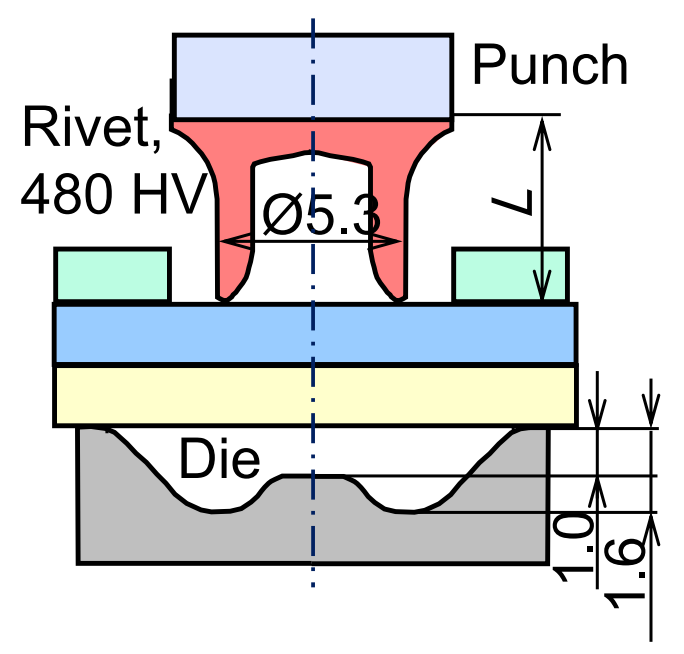

Fig. 7 Joining conditions of sheets by self-pierce riveting 


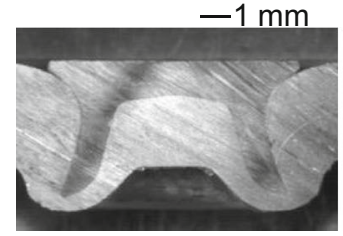

(a)

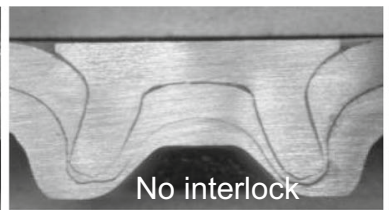

(b)

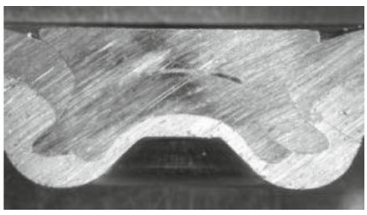

(c)

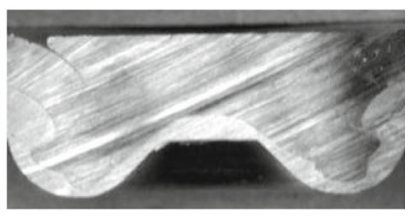

(d)

Fig. 8 Cross-sectional shape of riveted sheets for $L=5 \mathrm{~mm}$. a A5052-A5052; b JSC780-JSC780; $\mathbf{c}$ JSC780-A5052, $t=1.5 \mathrm{~mm}$; d JSC780-A5052, $t=1 \mathrm{~mm}$

95\%. As shown in Fig. 11b, the reduction tendency of the sheet thickness is similar to that of the load, and then the sheet thickness ratios of JAC780, JSC780, and A5052 at $T=1176 \mathrm{~h}$ are $93 \%, 69 \%$, and $96 \%$, respectively.

\subsection{Durability of joined aluminium alloy sheets}

The cross-sectional shapes and hardness of the joined aluminium sheets are shown in Fig. 12. The cross-sectional shapes of both the clinched and riveted sheets before and after corrosion test are similar. The gaps among the rivet and upper and lower sheets are not observed in both the clinched and riveted sheets before and after the corrosion test. The hardness in the crosssection of the clinched sheets from centre to around the die side wall was measured. The hardness distributions of the cross-section of the sheets before and after the test joined by mechanical clinching are similar. In the riveted sheets, the upper sheet around the top of the rivet was measured because the hardness was not changed in the clinched sheets. The hardness in the cross-section of the riveted sheets before and after the corrosion test is same.

The tension-shearing load-stroke curves of the two aluminium alloy sheets are shown in Fig. 13. The tension-shearing load of the clinched joints slightly decreases with increasing the corrosion time. The minimum thickness portion of the upper sheet is fractured, and the corrosion is observed at the sheet interface, whereas the corrosion is not observed around the joint at $T=1176 \mathrm{~h}$. The tendency of load of the riveted joint is similar to that of the mechanical clinched sheets. The rivet is pulled out from the lower sheet after the test. The corrosion occurs at the sheet interface at $T=1176 \mathrm{~h}$, although the corrosion of the rivet does not occur.

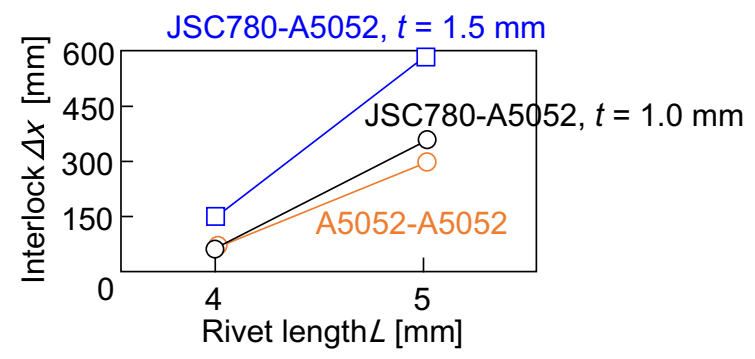

Fig. 9 Effect of rivet length on interlock
The relationship between the tension-shearing load of the two aluminium alloy sheets and the aging time is shown in Fig. 14. The load reductions by mechanical clinching and self-piercing riveting are $1 \%$ and $3 \%$, respectively. The reduction in the sheet thickness due to corrosion was very slight in Fig. 11, and the reduction in the hardness was not shown in Fig. 12b.

\subsection{Durability of joined steel sheets}

The cross-sectional shapes and the hardness of the joined steel sheets are shown in Fig. 15. As the aging time increases, the corrosion of deformed sheets progresses. In the two steel sheets without galvanized coating layer, the corrosion rate is higher than that of the two galvanized steel sheets, and then the minimum wall thickness portion completely disappears at $T=1176 \mathrm{~h}$. The increased corrosion rate may be accelerated by the salt water in the depression of the sheets. Although the wall thickness is decreased by the corrosion, the reduction in the hardness is not observed.

The distribution of the coated layer thickness on the upper surface of the two galvanized steel sheets is shown in Fig. 16. The coating layer thickness was measured at $T=672 \mathrm{~h}$ because the observation of the thickness was not easy at $T=$ $1176 \mathrm{~h}$ due to the severe corrosion. The coating layer thickness is about $30 \mu \mathrm{m}$ before the test. As $T=0 \mathrm{~h}$, the coating layer was stretched by the deformation in mechanical clinching, and then the thickness decreased at the bottom and side walls of the punch. The tendency is similar to reference [18]. At $T=672 \mathrm{~h}$, the corrosion progresses, and the coating layer disappears at the bottom and sidewall of the punch, and other portions also decreases.

The tension-shearing load-stroke curves of both the steel sheets are shown in Fig. 17. As the corrosion time increases, not only the maximum load but also the final stroke decreases.

The relationship among the tension-shearing load, the minimum wall thickness in the upper sheet of steel sheets, and the aging time is shown in Fig. 18. The load and the thickness ratios in the tensile test before and after the corrosion test in Fig. 11 are merged in Fig. 18. The load and the minimum wall thickness of the two steel sheets decrease with increasing the aging time. The reduction behaviour of the load and the minimum wall thickness is same, because the reduction in the minimum wall thickness leads to a reduction in load. The 
Fig. 10 Dimensions of specimens and test conditions for tensile test and tension-shearing test. a Specimens; b Test conditions

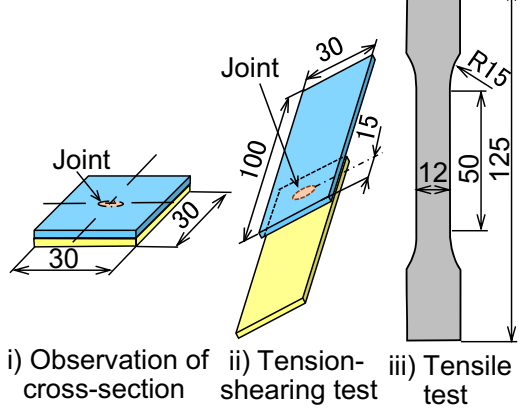

(a)

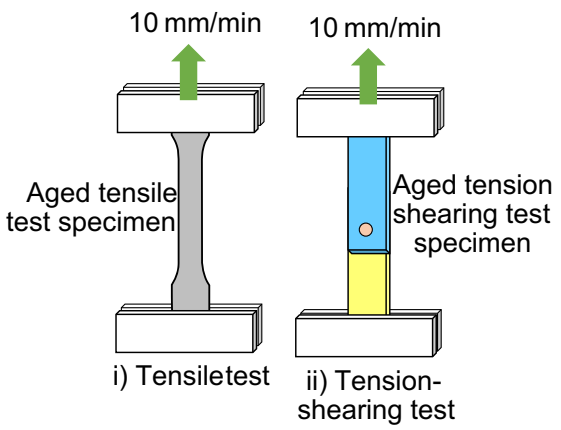

(b) reduction rate in the load and the minimum wall thickness are slower for the galvanized steel sheets because of the remained coated layer thickness in Fig. 16. The thickness ratio in both the clinched sheets before and after the corrosion test is lower than that of the tensile test specimen, i.e., the corrosion at the minimum thickness of the upper sheet progresses faster than the corrosion of the sheet without the joint.

\subsection{Durability of joined steel and aluminium alloy sheets}

The cross-sectional shapes and the hardness of the steel and aluminium alloy sheets are shown in Fig. 19. The gaps among the rivet and the upper and lower sheets are not observed in both the clinched and riveted sheets before the test. In the clinched sheets, the thickness decreases due to the corrosion around the minimum thickness of the upper sheet. The top surface on the edge of the lower aluminium alloy sheet corrodes due to the aluminium alloy sheet with a low-standard electrode potential, and the thickness decreases because the solution infiltrates from the sheet edge. The progress of corrosion does not reach the clinched portion at $T=1176 \mathrm{~h}$.
Although the reduction in the wall thickness causes after the corrosion, the hardness is not changed. In the riveted joined sheets, the top surface of the upper steel sheet and the upper surface of the lower aluminium alloy sheet are mainly corroded. The progress of corrosion does not reach the riveted portion at $T=1176 \mathrm{~h}$. The hardness after the corrosion test does not change.

The minimum thickness of the upper sheet and the lower sheet thickness were measured, and then the tension-shearing test was performed. The relationship among the tensionshearing load, the minimum wall thickness in the upper sheet, and the aging time is shown in Fig. 20. In the clinched sheets, the load decreases because the thickness decreases with increasing the aging time in both the sheet combinations. The reduction is moderate with the galvanized steel sheet. In the riveted sheets, the load and the average thickness of the lower sheet around the edge also decreases with increasing the aging time. The corrosion is observed at the sheet interface, whereas the corrosion is not observed around the joint in both the clinched and riveted sheets in Fig. 19. It seems that the load reduction was caused by the thickness reduction of the lower aluminium alloy sheet.
Fig. 11 Reduction in maximum tensile load of sheet and sheet thickness. a Tensile load; b Thickness

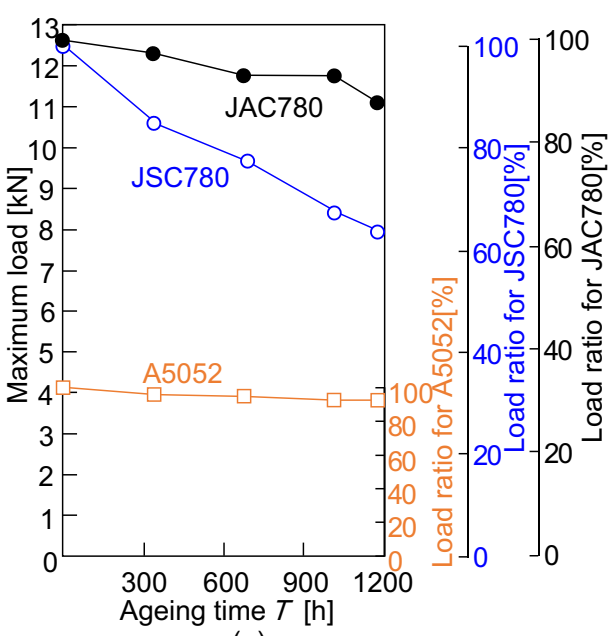

(a)

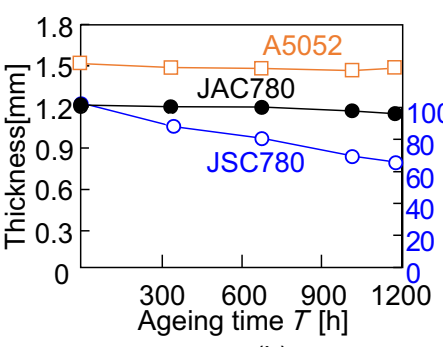

(b)

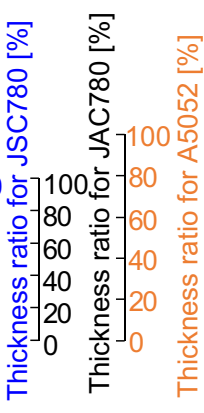



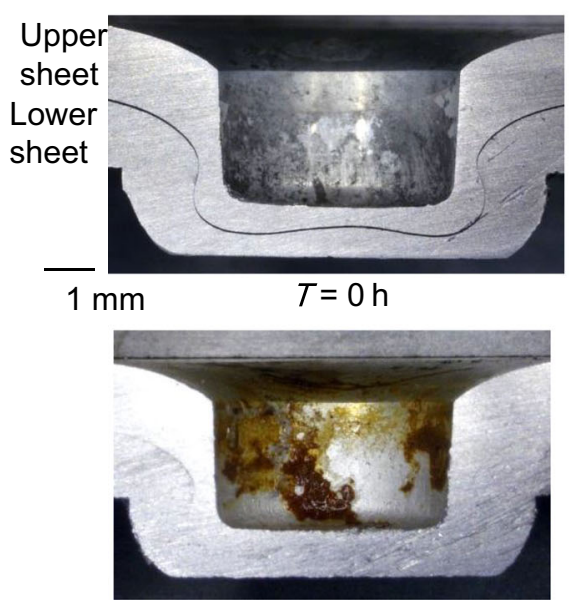

$T=1176 \mathrm{~h}$

i) Cross-sectional shape

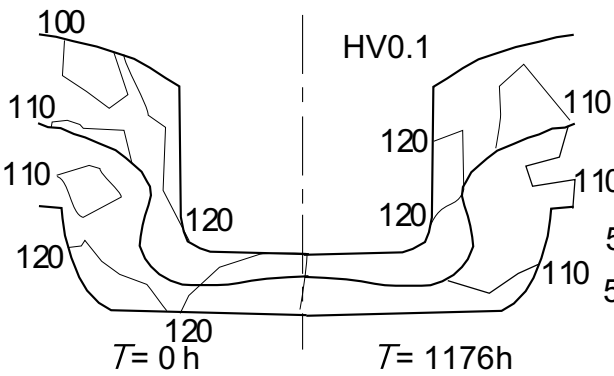

ii) Hardness distribution

(a)
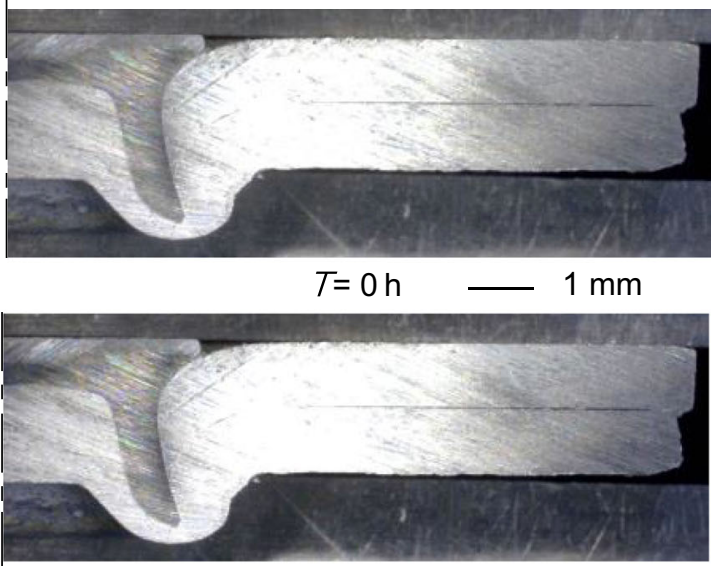

$T=1176 \mathrm{~h}$

i) Cross-sectional shape

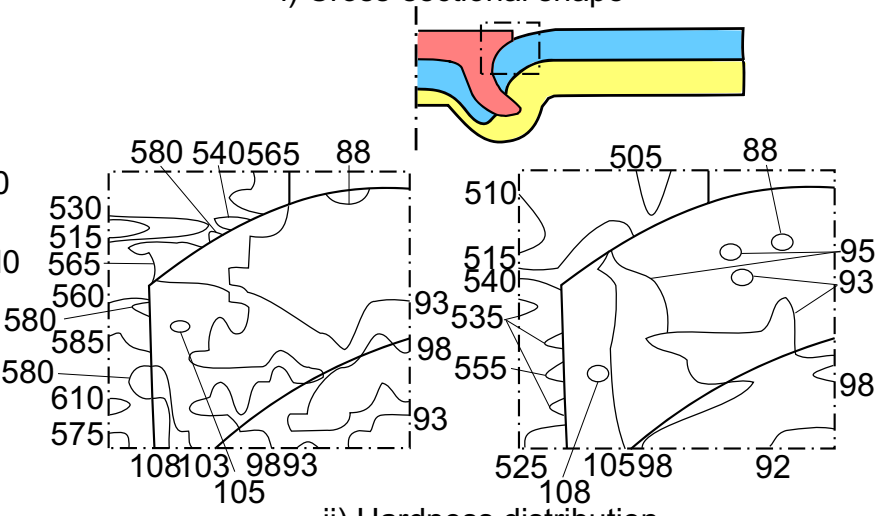

ii) Hardness distribution

Fig. 12 Cross-sectional shapes and hardness of joined A5052-A5052 sheets. a Clinched sheets; b Riveted sheets

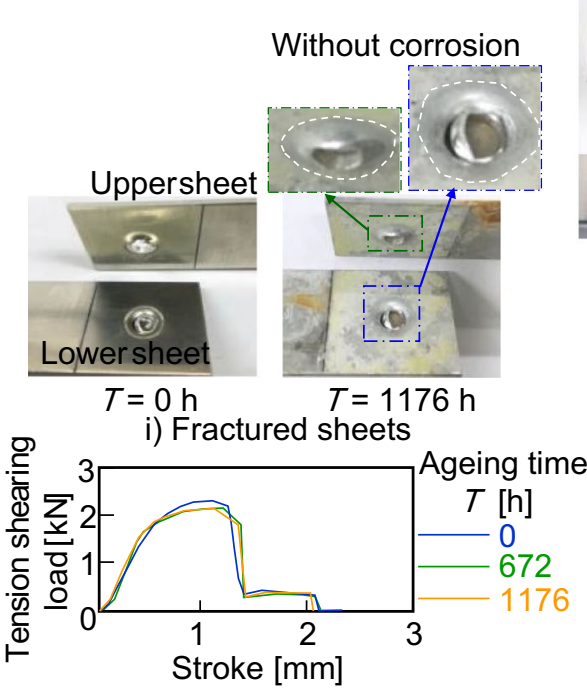

ii) Tension-shearing load-stroke curve

(a)
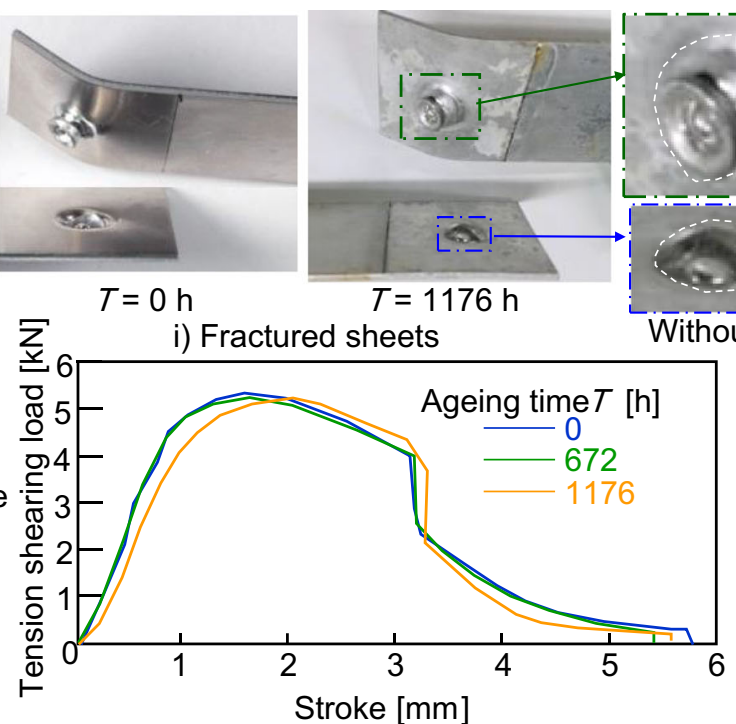

ii) Tension-shearing load-stroke curve

(b)

Fig. 13 Tension-shearing load-stroke curves of A5052-A5052 sheets. a Clinched sheets; b Riveted sheets 


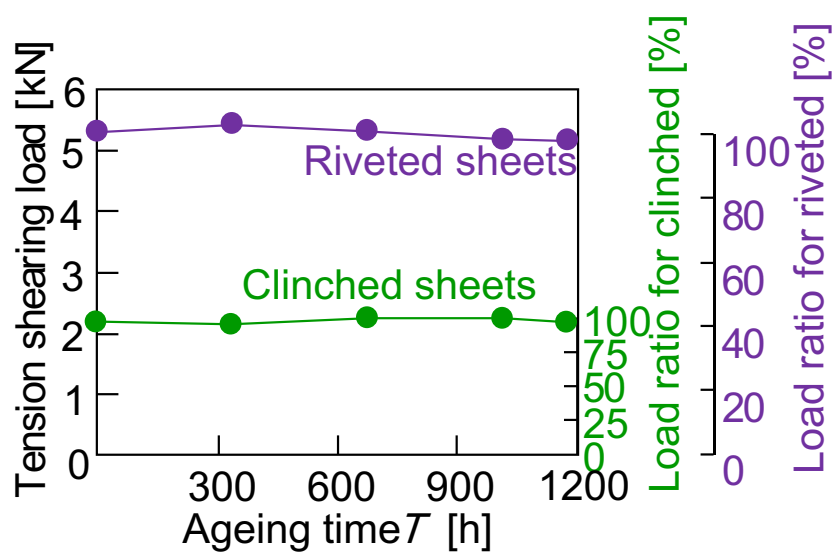

Fig. 14 Relationship between tension-shearing load of A5052-A5052 sheets and aging time

The corrosion in the thinner aluminium alloy sheet was investigated. The cross-sectional shapes of the steel and thin aluminium alloy sheets are shown in Fig. 21. The upper surface on the edge of the lower aluminium alloy sheet in the clinched and riveted sheets corrodes, i.e., the wall thickness in the portion, decreases as the same as in Fig. 19. It seems that the progress of the corrosion does not reach the joint portion at $T=1176 \mathrm{~h}$.
The relationship among the mean thickness of lower sheet, the minimum wall thickness in the upper sheet of the steel, and thin aluminium alloy sheets and the aging time is shown in Fig. 22. In the clinched sheets, the minimum thickness of the upper sheet and the average lower sheet thickness decrease with increasing the aging time, and the reduction rates of the thicknesses are similar. Even in the riveted sheets, the reduction rates of both the sheets are the same.

The relationship between the tension-shearing load of the steel and thin aluminium alloy sheets and the aging time is shown in Fig. 23. In both the clinched and riveted sheets, the upper sheet or the rivet is pulled out from the lower sheet. After the corrosion, the thickness of the lower sheet is reduced, and then the fracture area is widened. The load decreases with increasing of the aging time. Thus, the reduction of the load was caused by the thickness reduction of the lower aluminium alloy sheet in Fig. 22. Because the progress of the corrosion does not reach the joint even $T=1176 \mathrm{~h}$ in this sheet combinations and in the two aluminium alloy sheets in Fig. 13 , the corrosion in the joint was prevented by joining without the gaps in the joined cross-section; thus, the load reduction was mainly caused by the thickness reduction.

The reduction in the tension-shearing load by the salt spray test for $T=1176 \mathrm{~h}$ and the schematic illustrations of corrosion modes are summarized in Fig. 24. For the two aluminium

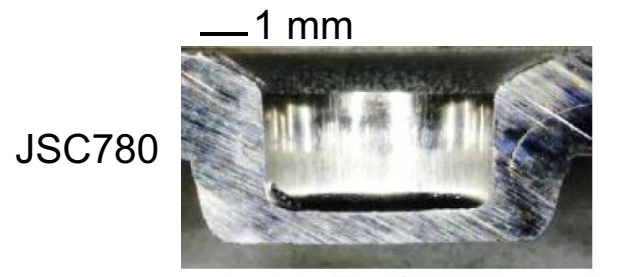

$T=0 \mathrm{~h}$

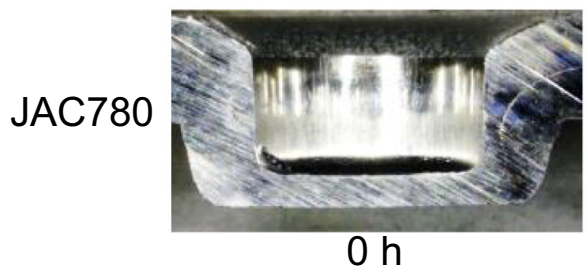

$\mathrm{Oh}$

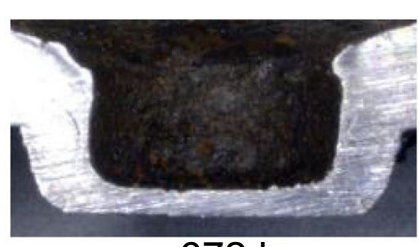

672 h

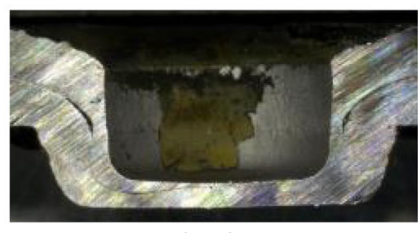

$672 \mathrm{~h}$

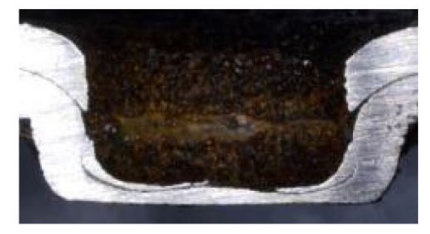

$1176 \mathrm{~h}$

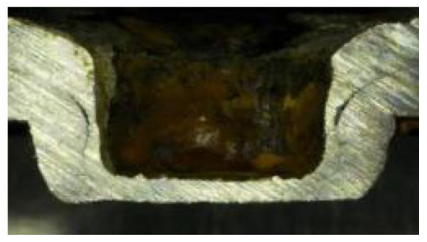

$1176 \mathrm{~h}$

(a)

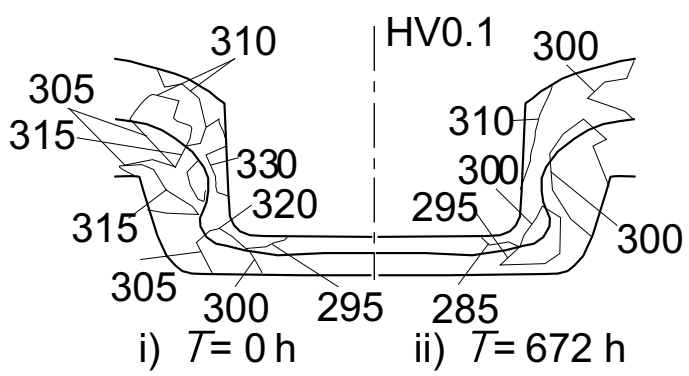

(b)

Fig. 15 Cross-sectional shapes and hardness of steel sheets. a Cross-sectional shape; b Hardness distribution for JSC780 
Fig. 16 Distribution of coated layer thickness on upper surface of JAC780 sheets

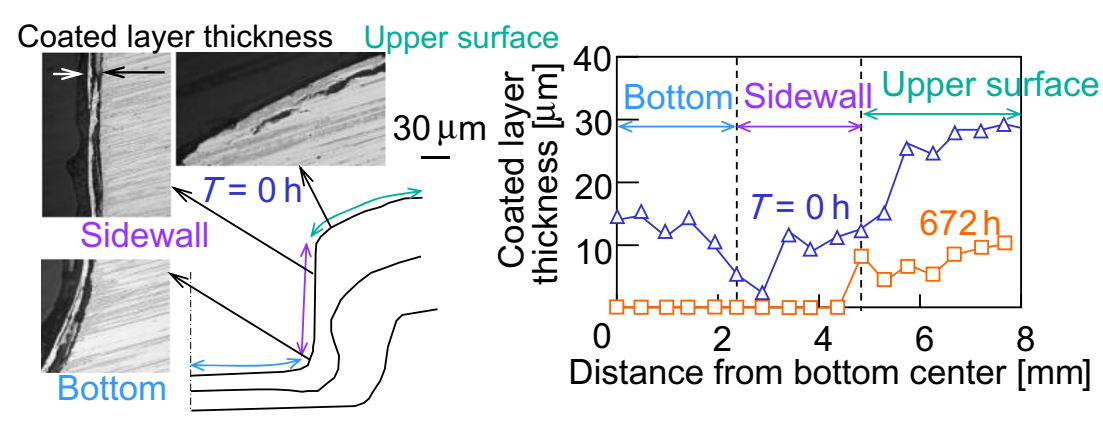

Fig. 17 Tension-shearing loadstroke curve of steel sheets. a JSC780; b JAC780

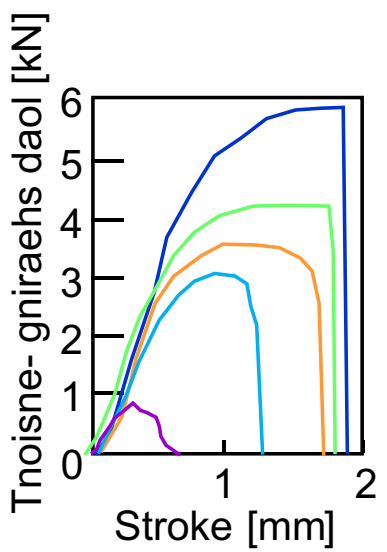

(a)

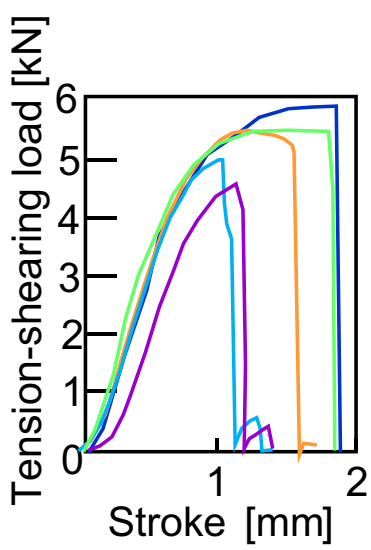

(b)
Ageing time $T[\mathrm{~h}]$

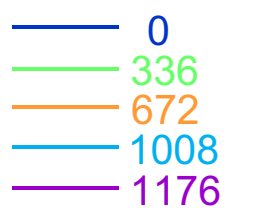

alloy sheets, the slight corrosion was observed on the surface and the sheet interface. The load of the riveted sheets is more than twice that of the clinched ones. The load reduction is only a few percent in both the clinched and riveted sheets. The mechanically clinched both the steel sheets without the galvanized coating layer were severely corroded around the side wall of the depression, with a reduction of $85 \%$. In the two galvanized steel sheets, the corrosion decreases and the load decreases by $24 \%$. In the sheet combination of the steel and aluminium alloy, the load of the riveted sheets is about 1.4 times of that of the clinched ones. In the sheet combination of the steel without galvanized coating layer and aluminium alloy, the loads decrease by about $20 \%$ in both the clinched and riveted sheets. The galvanized steel and aluminium alloy sheets decrease by about $11 \%$. In the sheet combination of the steel and aluminium alloy sheets, the sever corrosion

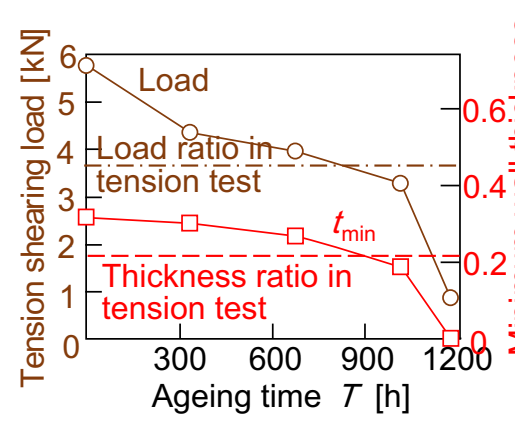

(a)
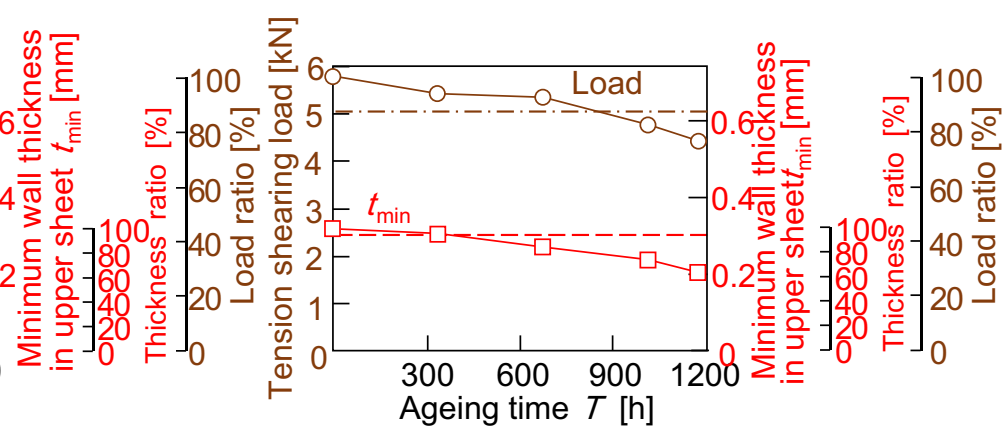

(b)

Fig. 18 Relationship among tension-shearing load, minimum wall thickness in upper sheet of steel sheets, and aging time. a JSC780; b JAC780 

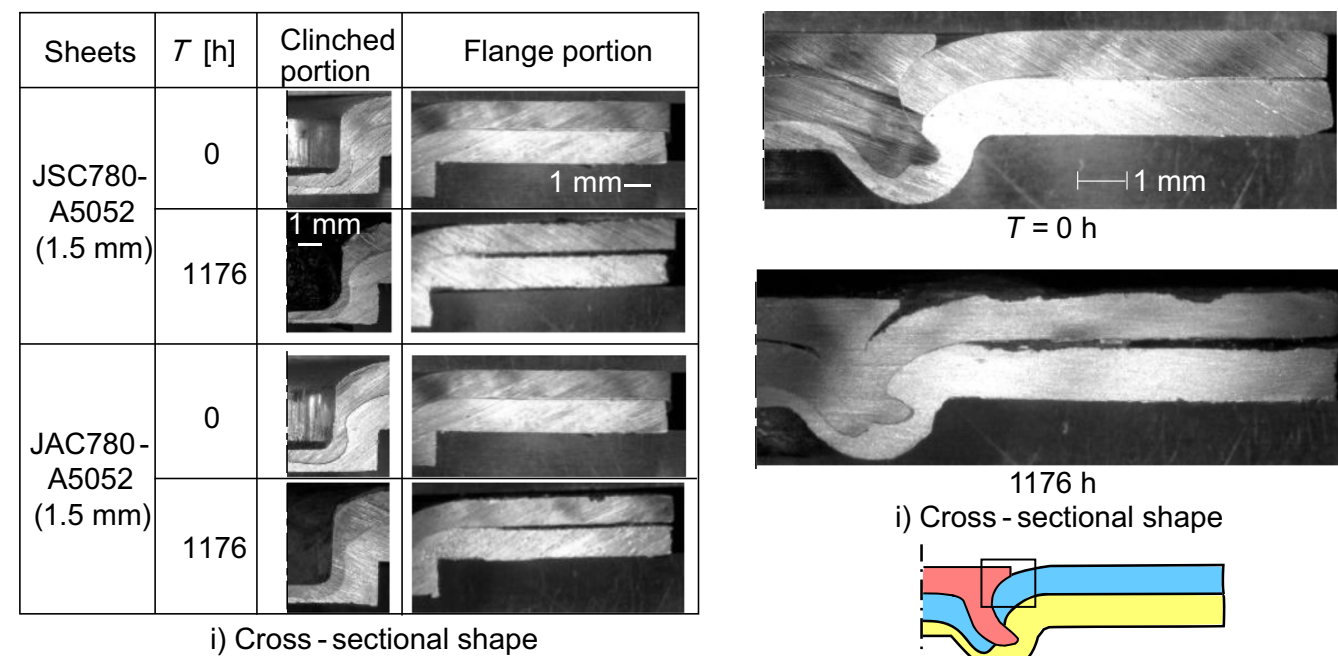

$1176 \mathrm{~h}$

i) Cross - sectional shape

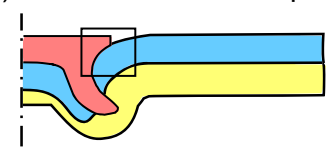

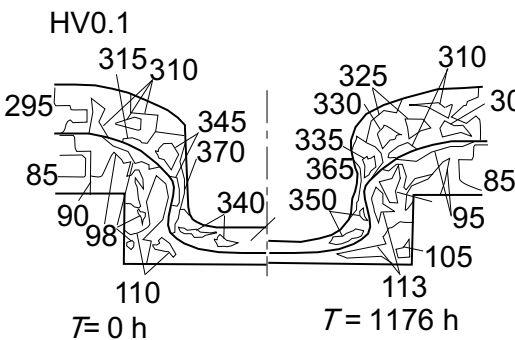

ii) Hardness distribution for JSC780

(a)

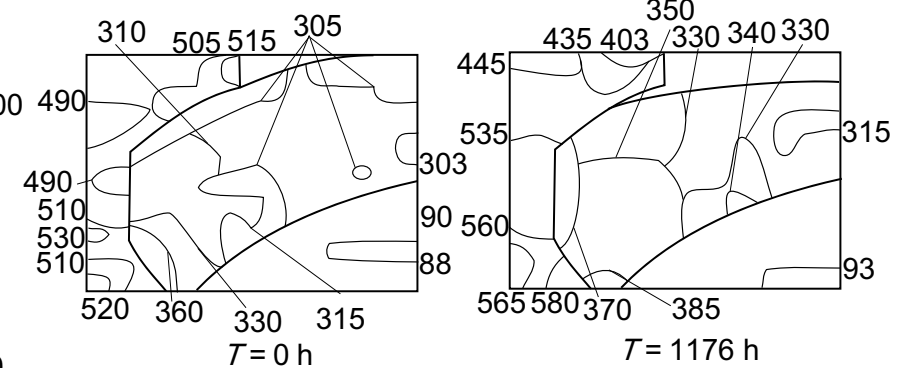

ii) Hardness distribution for JSC780

(b)

Fig. 19 Cross-sectional shapes and hardness of steel-A5052 sheets. a Clinched sheets; b Riveted sheets

Fig. 20 Relationship among tension-shearing load, minimum wall thickness in upper sheet, and aging time for of steel-A5052 $(t=$ $1.5 \mathrm{~mm})$. a Clinched sheets; $\mathbf{b}$ Riveted sheets

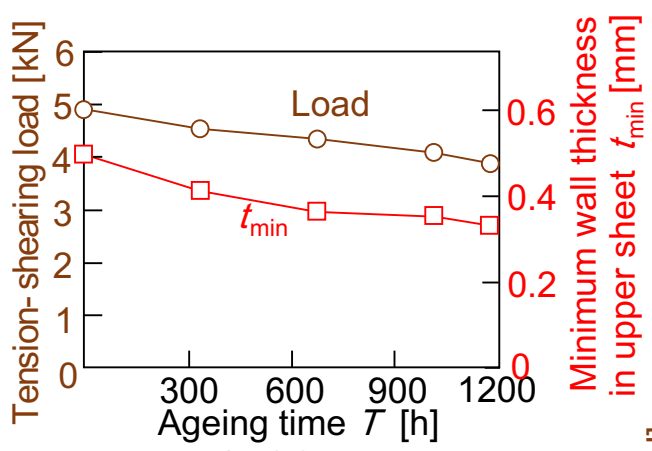

i) JSC780

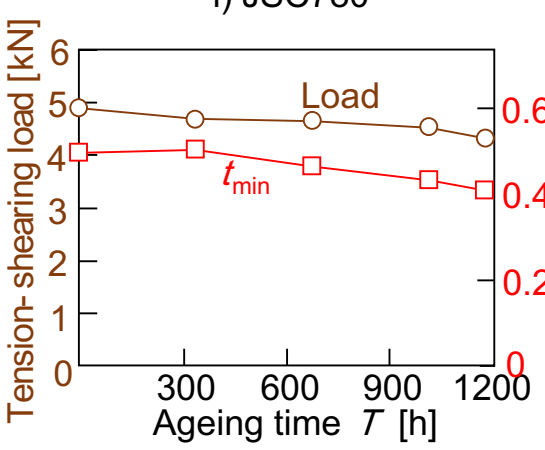

ii) JAC780

(a)

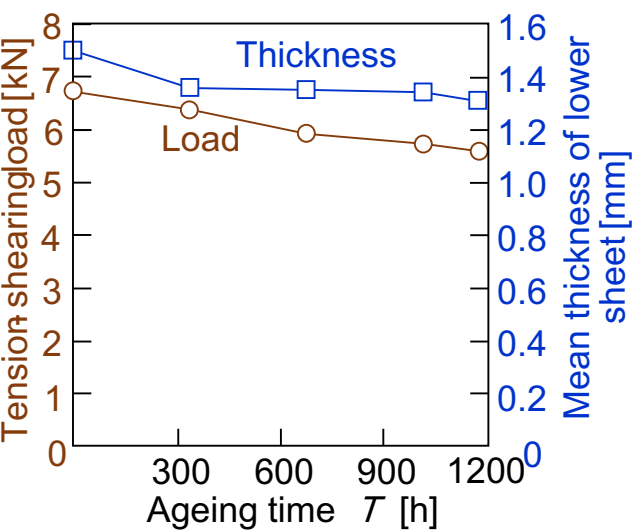

(b) 


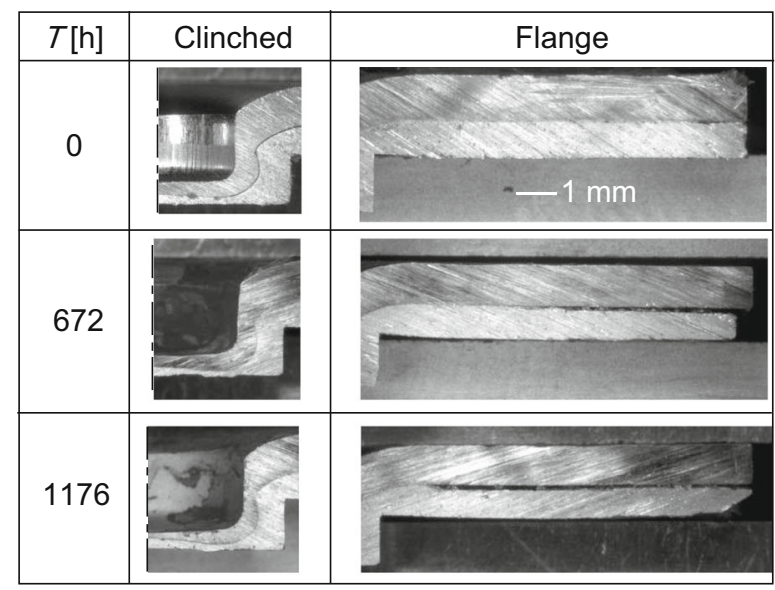

(a)

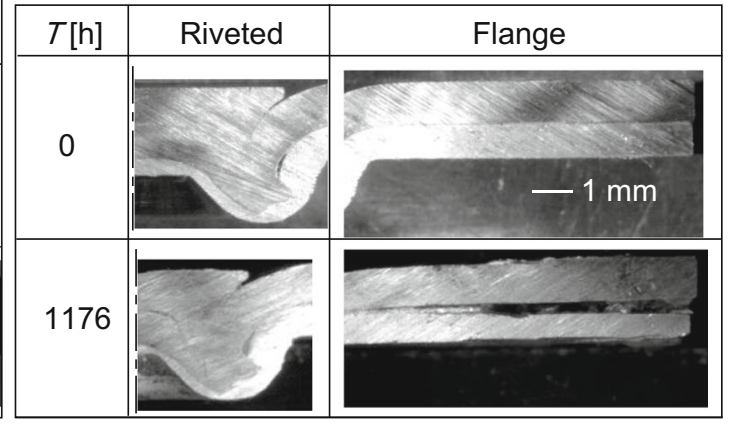

(b)

Fig. 21 Cross-sectional shapes of steel-A5052 $(t=1 \mathrm{~mm})$ sheets. a Clinched sheets; b Riveted sheets

Fig. 22 Relationship among mean thickness of lower sheet, minimum wall thickness in upper sheet of steel-A5052 $(t=1 \mathrm{~mm})$ sheets, and aging time. a Clinched sheets; b Riveted sheets
Fig. 23 Relationship between tension-shearing load of steelA5052 $(t=1 \mathrm{~mm})$ sheets and aging time

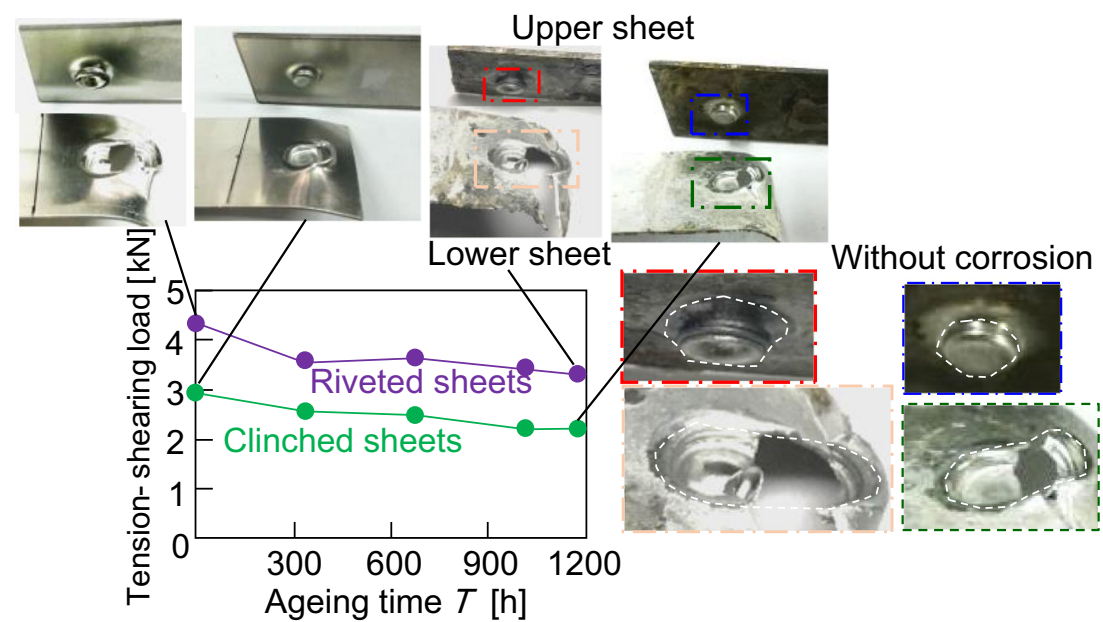




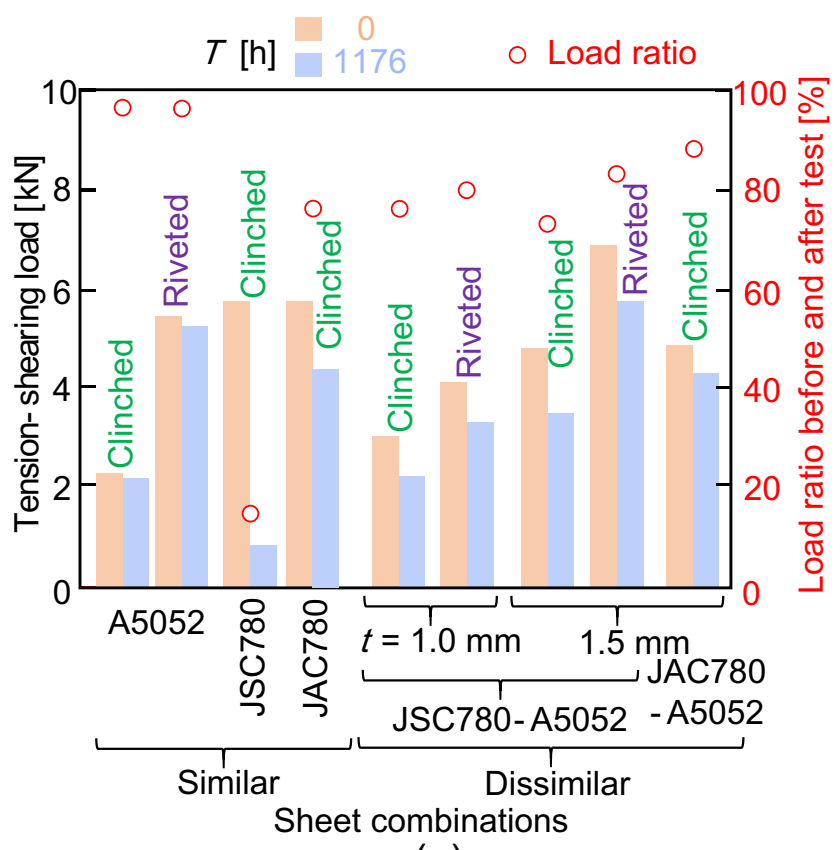

(a)
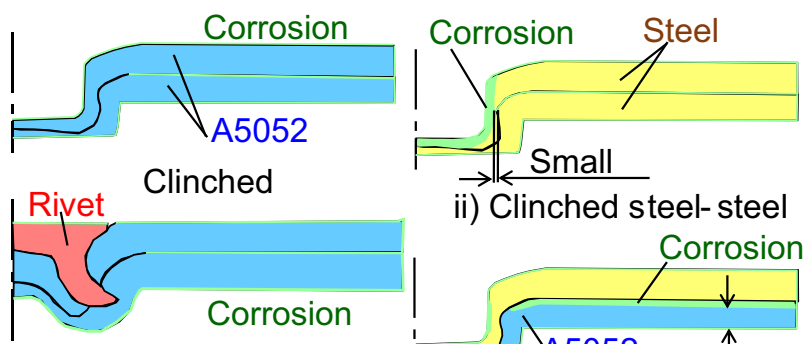

ii) Clinched steel-steel

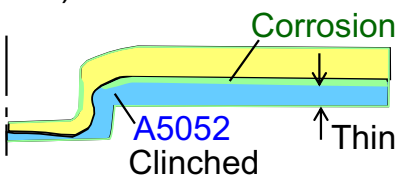

i) A5052- A5052

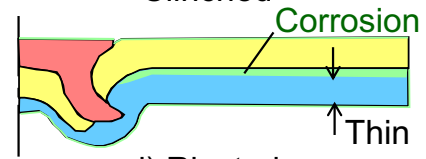

i) Riveted

(b)

iii) Steel - A5052

Fig. 24 Reduction in tension-shearing load by salt spray test for $T=$ $1176 \mathrm{~h}$ and schematic illustration of corrosion mode in sheet combinations. a Reduction in tension shearing load; $\mathbf{b}$ Corrosion modes

was observed on the upper surface in the lower sheet. The use of the galvanized steel sheets is effective in the decrease of load reduction.

\section{Conclusions}

In this study, the 780-MPa high-strength steel and aluminium alloy A5052 sheets were joined by mechanical clinching and self-pierce riveting, and the salt spray test was performed to measure the corrosion behaviour and strength reduction, and the following results were obtained:
(1) Except for the two steel sheets by self-pierce riveting, all sheet combinations including the two steel sheets, the two aluminium alloy sheets, and the steel-aluminium alloy sheets were successfully joined by mechanical clinching and self-pierce riveting without the gaps among the rivet and sheets.

(2) The corrosion in the joined both the aluminium alloy sheets was little, and the reduction in the tension-shear load before and after the corrosion was $1 \%$ and $3 \%$ for the clinched and riveted sheets, respectively. The load of the riveted sheets was more than twice of that of clinched ones.

(3) The corrosion of the clinched both the steel sheets without the galvanized coating layer progressed more than the corrosion in the tensile test specimen without the joint, and then the load decreased by $85 \%$. In the two galvanized steel sheets, the progress of corrosion slowed down by $24 \%$, whereas the coating layer thickness on the surface was reduced by the deformation of the sheets.

(4) In the clinched steel and aluminium alloy sheets, the thickness reduction occurred near the minimum thickness of the upper sheet and the upper surface on the edge of the lower aluminium alloy sheet due to the corrosion. In the riveted sheets, the upper surface on the edge of the lower aluminium alloy sheet was observed. Because the progress of corrosion did not reach the joint even 1176 hours in this sheet combination and in the two aluminium alloy sheets, the corrosion in the joint was prevented by joining without the gaps in the joined cross-section; thus, the load reduction was mainly caused by the mean thickness reduction.

(5) The load of the steel sheet without galvanized coating layer and aluminium alloy sheets decreased by about $20 \%$ in both the clinched and riveted sheets. The load of the galvanized steel and aluminium alloy sheets decreased by about $11 \%$; thus, the use of the galvanized steel sheets was effective for the decrease of the load reduction.

Acknowledgments The authors would like to thank Zhichao Dai and Takuki Itani for performing the joining experiments and salt spray tests. The authors greatly acknowledged Bellsonica Co., Ltd. for using salt spray test instrument. The joining tools are manufactured in a cooperative research facility centre in Toyohashi University of Technology

Authors' contributions Conceptualization, Ken-ichiro Mori; methodology and investigation, Yohei Abe and Ken-ichiro Mori; writing-original draft preparation and visualization-Yohei Abe; supervision, Ken-ichiro Mori.

\section{Compliance with ethical standards}

Competing interests The authors declare that they have no competing interests.

Ethical approval The article involves no studies on human or animal subjects. 
Open Access This article is licensed under a Creative Commons Attribution 4.0 International License, which permits use, sharing, adaptation, distribution and reproduction in any medium or format, as long as you give appropriate credit to the original author(s) and the source, provide a link to the Creative Commons licence, and indicate if changes were made. The images or other third party material in this article are included in the article's Creative Commons licence, unless indicated otherwise in a credit line to the material. If material is not included in the article's Creative Commons licence and your intended use is not permitted by statutory regulation or exceeds the permitted use, you will need to obtain permission directly from the copyright holder. To view a copy of this licence, visit http://creativecommons.org/licenses/by/4.0/.

\section{References}

1. Barnes TA, Pashby IR (2000) Joining techniques for aluminum spaceframes used in automobiles. Part II - adhesive bonding and mechanical fasteners. J Mater Process Technol 99(1):72-79

2. Nong N, Keju O, Yu Z, Zhiyuan Q, Changcheng T, Feipeng L (2003) Research on press joining technology for automotive metallic sheets. J Mater Process Technol 137(1-3):159-163

3. He X (2017) Clinching for sheet materials. Sci Technol Adv Mater 18(1):381-405

4. Lee CJ, Kim JY, Lee SK, Ko DC, Kim BM (2010) Design of mechanical clinching tools for joining of aluminium alloy sheets. Mater Des 31:1854-1861

5. Varis JP (2003) The suitability of clinching as a joining method for high-strength structural steel. J Mater Process Technol 132(1-3): 242-249

6. Abe Y, Saito T, Mori K et al (2018) Mechanical clinching with dies for control of metal flow of ultra-high-strength steel and highstrength steel sheets. Proc Inst Mech Eng B J Eng Manuf 232(4): 644-649

7. Chen LW, Huang JM, Hsu YC (2015) Investigation of the clinching process combines with hot stamping process for highstrength steel sheets. MATEC Web Conf 21:05004

8. Abe Y, Kato T, Mori K (2007) Joining of aluminium alloy and mild steel sheets using mechanical clinching. Mater Sci Forum 561-565: 1043-1046

9. Abe Y, Mori K, Kato T (2012) Joining of high-strength steel and aluminium alloy sheets by mechanical clinching with dies for control of metal flow. J Mater Process Technol 212:884-889

10. Lambiase F, Ko DC (2017) Two-steps clinching of aluminum and carbon fiber reinforced polymer sheets. Compos Struct 164:180188
11. Behrens BA, Bouguecha A, Vucetic M et al (2015) FEA-based optimisation of a clinching process with a closed single-part die aimed at damage minimization in CR240BH-AlSi10MnMg joints. Key Eng Mater 651-653:1487-1492

12. Mori K, Bay N, Fratini L (2013) Joining by plastic deformation. CIRP Ann 62(2):673-694

13. Cai W, Wang PC, Yang W (2005) Assembly dimensional prediction for self-piercing riveted aluminum panels. Int J Mach Tool Manu 45(6):695-704

14. Ma Y, Lou M, Li Y, Lin ZQ (2018) Effect of rivet and die on selfpiercing rivetability of AA6061-T6 and mild steel CR4 of different gauges. J Mater Process Technol 251:282-294

15. Abe Y, Kato T, Mori K (2009) Self-piercing riveting of high tensile strength steel and aluminium alloy sheets using conventional rivet and die. J Mater Process Technol 209(8):3914-3922

16. Han L, Chrysanthou A (2008) Evaluation of quality and behaviour of self-piercing riveted aluminium to high strength low alloy sheets with different surface coatings. Mater Des 29:458-468

17. Settineri L, Atzeni E, Ippolito R (2010) Self piercing riveting for metal-polymer joints. Int J Mater Form 3(1):995-998

18. Abe Y, Kato T, Kishimoto M et al (2010) Joining of hot-dip coated high-strength steel sheets by mechanical clinching. Steel Res Int 81(9):1128-1131

19. Pinger T, Rückriem EM (2016) Investigation on the corrosion and mechanical behavior of thin film batch galvanized thick plate components in clinch joints. Int J Adv Manuf Technol 86:29-36

20. Jandaghi MR, Pouraliakbar H (2018) Elucidating the microscopic origin of electrochemical corrosion and electrical conductivity by lattice response to severe plastic deformation in Al-Mn-Si alloy. Mater Res Bull 108:195-206

21. Calabrese L, Bonaccorsi L, Proverbio E, di Bella G, Borsellino C (2013) Durability on alternate immersion test of self-piercing riveting aluminium joint. Mater Des 46:849-856

22. Ioannou J (2009) Mechanical behaviour and corrosion of interstitial-free steel to aluminium alloy self-piercing riveted joints, $\mathrm{PhD}$ thesis, in School of Engineering and Technology, University of Hertfordshire, UK

23. Calabrese L, Proverbio E, Galtieri G, Borsellino C (2015) Effect of corrosion degradation on failure mechanisms of aluminium/steel clinched joints. Mater Des 87:473-481

24. Calabrese L, Proverbio E, Di Bella G et al (2015) Failure behaviour of SPR joints after salt spray test. Eng Struct 82:33-43

25. LeBozec N, LeGac A, Thierry D (2012) Corrosion performance and mechanical properties of joined automotive materials. Mater Corros 63-5:408-415

Publisher's note Springer Nature remains neutral with regard to jurisdictional claims in published maps and institutional affiliations. 